\title{
Magnesium deficiency associated with diabetic retinopathy in type 2 diabetes mellitus: A meta-analysis
}

\author{
Ronald Pratama Adiwinoto ${ }^{1}$, Robert Dwitama Adiwinoto ${ }^{2}$, Jongky Hendro Prajitno ${ }^{3}$ \\ ${ }^{1}$ Department of Public Health and Preventive Medicine, Hang Tuah University Faculty of Medicine, Indonesia \\ ${ }^{2}$ Postgraduate School of Medicine, Airlangga University Faculty of Medicine, Indonesia \\ ${ }^{3}$ Division of Endocrinology, Diabetes, and Metabolism, Department of Internal Medicine, Airlangga University Faculty \\ of Medicine, Dr. Soetomo Teaching Hospital, Indonesia
}

\begin{tabular}{l}
\hline \hline Article Info \\
\hline Article history: \\
Received Feb 27, 2021 \\
Revised Jun 9, 2021 \\
Accepted Jun 21, 2021 \\
\hline
\end{tabular}

Keywords:

Diabetic retinopathy

Magnesium

Meta-analysis

Type 2 diabetes mellitus

\begin{abstract}
Diabetic retinopathy (DR) is the major cause of visual impairment in the working-age population with type 2 diabetes mellitus (T2DM). Magnesium $(\mathrm{Mg})$ is involved in various metabolic processes and in experimental animal studies; $\mathrm{Mg}$ has shown essential roles in physiological eye function. Magnesium deficiency is common in T2DM; therefore we analyzed the association between serum $\mathrm{Mg}$ status and the presence of DR in T2DM patients. Systematic literature searching in several databases, from 1988 to September 2020, was performed using search terms: "serum magnesium" or "hypomagnesemia" and "diabetic retinopathy" or "retinopathy". A total of 3,227 patients from 17 studies were included in this meta-analysis. Hypomagnesemia was associated with increased risk of developing DR (OR 4.52 [2.08, 9.81], $\mathrm{p}=0.0001$ ) in T2DM patients. Serum $\mathrm{Mg}$ levels also lower in patients with DR than those without DR (MD $-0.30 \mathrm{mg} / \mathrm{dL}[-0.44,-0.15]$, $\mathrm{p}<0.0001)$. Additionally, serum $\mathrm{Mg}$ levels were lower in patients with proliferative DR (PDR) than those with non-proliferative DR (NPDR) (MD$0.21 \mathrm{mg} / \mathrm{dL}[-0.34,-0.09], \mathrm{p}=0.0009)$. Leave-one-out sensitivity analysis did not change the overall effect. Hypomagnesemia or low serum $\mathrm{Mg}$ levels in T2DM patients increased the risk of developing DR.
\end{abstract}

This is an open access article under the CC BY-SA license.

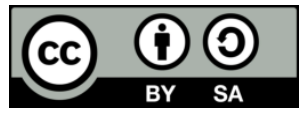

\section{Corresponding Author:}

Robert Dwitama Adiwinoto

Postgraduate School of Medicine

Airlangga University Faculty of Medicine

47 Mayjen Prof. Dr. Moestopo Road, Surabaya 60132, Indonesia

Email: dr.robert.dwi@gmail.com

\section{INTRODUCTION}

Diabetes mellitus (DM) is a major public health problem, affecting over 300 million individuals worldwide, and T2DM is estimated to be $95 \%$ of all diagnosed cases [1], [2]. Multi-system long term complications of T2DM also had significant morbidity and affect the quality of life in these patients. Diabetic retinopathy is a highly specific neurovascular complication of diabetes and is the most common cause of visual impairment in the working-age population [3]-[5]. The prevalence of DR from previous study was $35 \%$ in people with DM and 10\% already in vision-threatening stages [3]. The incidence of blindness may be reduced up to $90 \%$ with the current surgical and medical techniques. The pathogenesis of DR involved a complex biochemical mechanism associated with hyperglycemia. These include oxidative stress, and advanced glycation end-products (AGEs) formation [6]. However, the link between hyperglycemia and retinal vascular lesions remains unclear; also several therapeutic agents targeted those biochemical pathways have yet to show promising results [7]. 
Magnesium is the fourth most common cation in the body and the second most common intracellular cation [8]. Magnesium is essential in many fundamental biochemical processes, including energy metabolism and nucleic acid synthesis. Deficiency of $\mathrm{Mg}$ is fairly common and multifactorial [9]. The prevalence of $\mathrm{Mg}$ deficiency in DM patients is estimated to be 25-39\%. Although the exact mechanism of $\mathrm{Mg}$ deficiency in patients with diabetes is not completely understood, osmotic diuresis contributes for majority of the $\mathrm{Mg}$ loss. Glucosuria in the diabetic state impairs renal tubular reabsorption of $\mathrm{Mg}$ from the glomerular filtrate. Hypomagnesemia, in turn, might worsen glycemic control in T2DM patients, as it is involved in insulin secretion, binding, and activity [8], [10]-[12].

Although the relationship between serum $\mathrm{Mg}$ and insulin resistance is well documented, the association between serum $\mathrm{Mg}$ and diabetic complications, especially DR, are still unclear [13]-[16]. In experimental animal studies, $\mathrm{Mg}$ has shown essential roles in eye development and physiological function [17], [18]. Several observational studies have explored the association between serum Mg and DR. A systematic review also has been conducted to investigate the association between micronutrients, including $\mathrm{Mg}$, and DR [16]. However, to our knowledge, there is no meta-analysis evaluating the association between the two yet. Therefore, our present study intended to evaluate the association between serum $\mathrm{Mg}$ status and the presence of DR in T2DM patients.

\section{RESEARCH METHOD}

This meta-analysis was carried out according to Preferred Reporting Items for Systematic Reviews and Meta-Analyses (PRISMA) statement.

\subsection{Eligibility criteria}

All articles in adult T2DM patients evaluating the association between serum Mg and DR with information regarding serum $\mathrm{Mg}$ status or levels, and the presence of DR as outcome were included in this meta-analysis. Articles such as: case report or case series, review articles, letters to editor, editorial or commentaries, animal studies, and non-English articles were excluded.

\subsection{Database search and study selection}

We searched the PubMed, EuropePMC, ScienceDirect, Cochrane Central databases and Google Scholar from 1988 to September 2020 using search terms: "serum magnesium" or "hypomagnesemia" and "diabetic retinopathy" or "retinopathy". Full text of all articles including the cross references related to our topics were retrieved; duplicates then removed. Authors (R.P.A, R.D.A) then screened the articles independently by its abstracts for relevance. The articles were thoroughly reviewed and only those which met the eligibility criteria were analyzed. Dispute among investigators was resolved through discussion and consultation with the senior investigator (J.H.P).

\subsection{Data extraction}

Data from included studies were extracted independently using a piloted data extraction form by two authors (R.P.A, R.D.A). The data extraction form included the authors' last name, year of the study, study location, study design, sample size, serum $\mathrm{Mg}$ assay method, the prevalence of hypomagnesemia, serum $\mathrm{Mg}$ levels, number of cases with DR, and PDR/NPDR (if present). Hypomagnesemia was defined according to the study reference value respectively, which cut-off value ranging from 1.5-1.8 $\mathrm{mg} / \mathrm{dL}$. Serum Mg levels means and SDs was presented in $\mathrm{mg} / \mathrm{dL}$ and measurements in $\mathrm{mmol} / \mathrm{L}$ were converted to $\mathrm{mg} / \mathrm{dL}$.

\subsection{Study quality}

The quality of the study was assessed using modified newcastle-ottawa scale (NOS) [19], [20]. The modified NOS encompass 3 domains: selection of participants, comparability of the participant group, and exposure ascertainment, comprises of total 10 items with 10 is the maximum score. A score of $\geq 7$ was considered to be a high-quality study. Two investigators (R.P.A, R.D.A) assessed the quality of the studies selected independently.

\subsection{Statistical analysis}

Meta-analysis was performed using Review Manager 5.4 (The Cochrane Collaboration, 2020) and comprehensive meta analysis (CMA) program version 3. Mantel-Haenszel formula was used to calculate dichotomus variables. Continuous variables were calculated using inverse-variance method. Random effects models were used despite the heterogeneity. Odds ratios (ORs) and mean differences (MDs) were reported with $95 \%$ confidence intervals (CIs). The p-value was two tailed and statistical significance of $\leq 0.05$ was used. 
Statistical heterogeneity was calculated with the $\mathrm{I}^{2}$ test and the Q-statistic test. $\mathrm{I}^{2}$ test $>50 \%$ indicated substantial heterogeneity across the studies. Leave-one-out analysis also performed to assess how each individual study affects the overall estimate of the rest of the studies should significant heterogeneity present. In addition, subgroup analysis was performed to explore other causes of heterogeneity. Funnel plot was used to assess for publication bias; an asymmetrical shape indicates publication bias. The regression-based Egger's test was performed to assess small-study effect.

\section{RESULTS AND DISCUSSION}

\subsection{Results}

\subsubsection{Study characteristics and selection}

We found a total of 547 records, and after duplicates were removed, 469 records remained. After thoroughly screening and evaluating the abstracts, 27 studies were included for full-text article assessment. However, five studies did not define the type of diabetes included and four studies presented unusable statistical data; thus they were excluded from this present study. Eighteen studies were included for methodological quality assessment according to modified NOS. One study scored below 7 and then excluded Figure 1. The average modified NOS of the studies included in this meta-analysis were 7.82 and only high quality studies were included (supplementary Table S1 and S2). The characteristics of the included studies are described in Table 1.

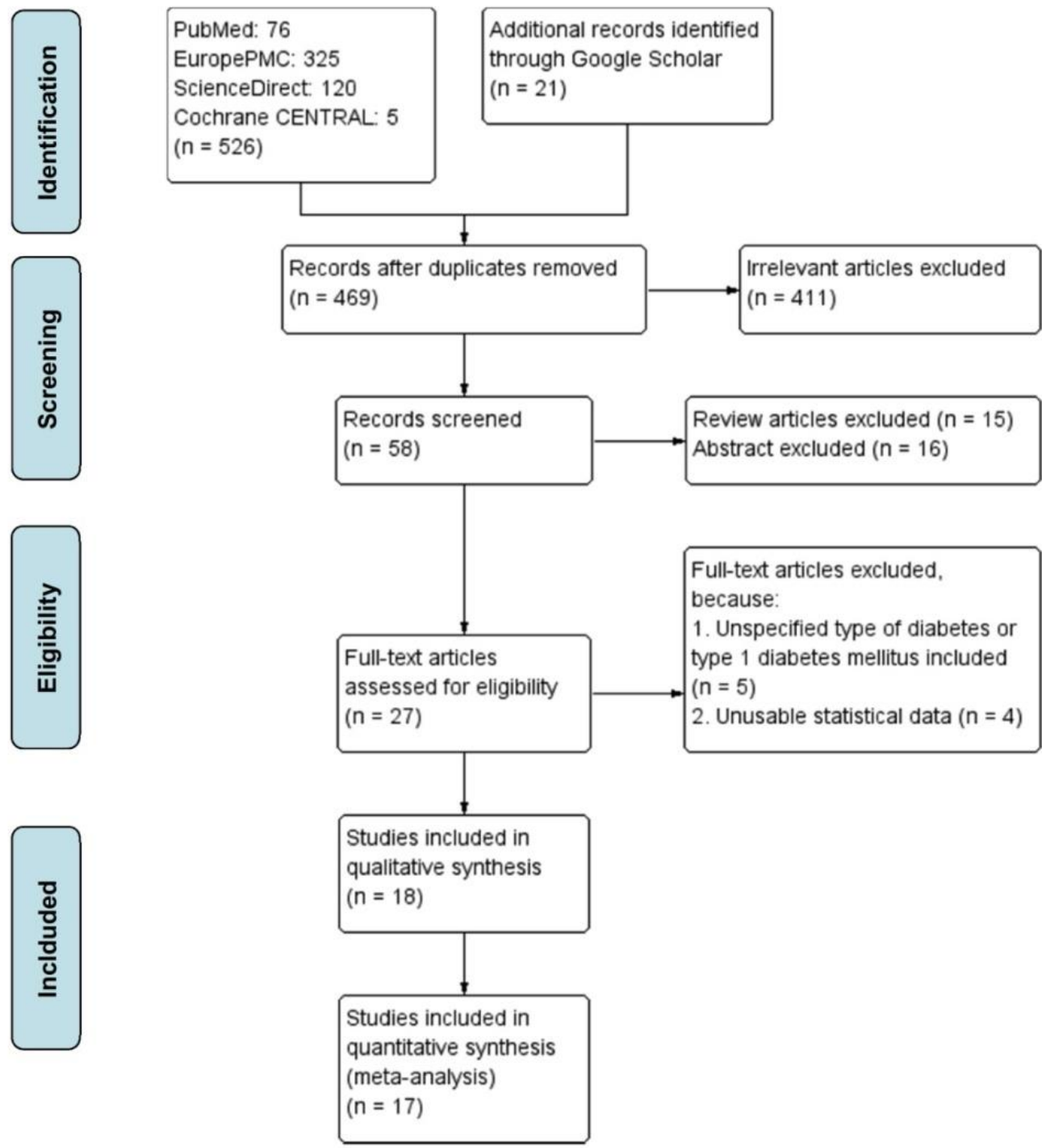

Figure 1. PRISMA flow diagram 
There were a total of 3,227 patients from 17 studies, among which 13 studies conducted in India. All the studies included were observational in design, either cross-sectional or case-control. Three different assay methods were used to measure serum Mg levels. The diagnosis of DR were based on primary data from eye examinations, interview, or through medical records for history of DR treatments. Eight studies reported the association of hypomagnesemia and the presence/absence of DR [21]-[28]. Seven studies reported the comparison of serum magnesium levels in the group of subjects with DR and without DR [29]-[35]. Two studies reported both informations in the full-text articles [36], [37].

Table 1. Characteristics of the included studies

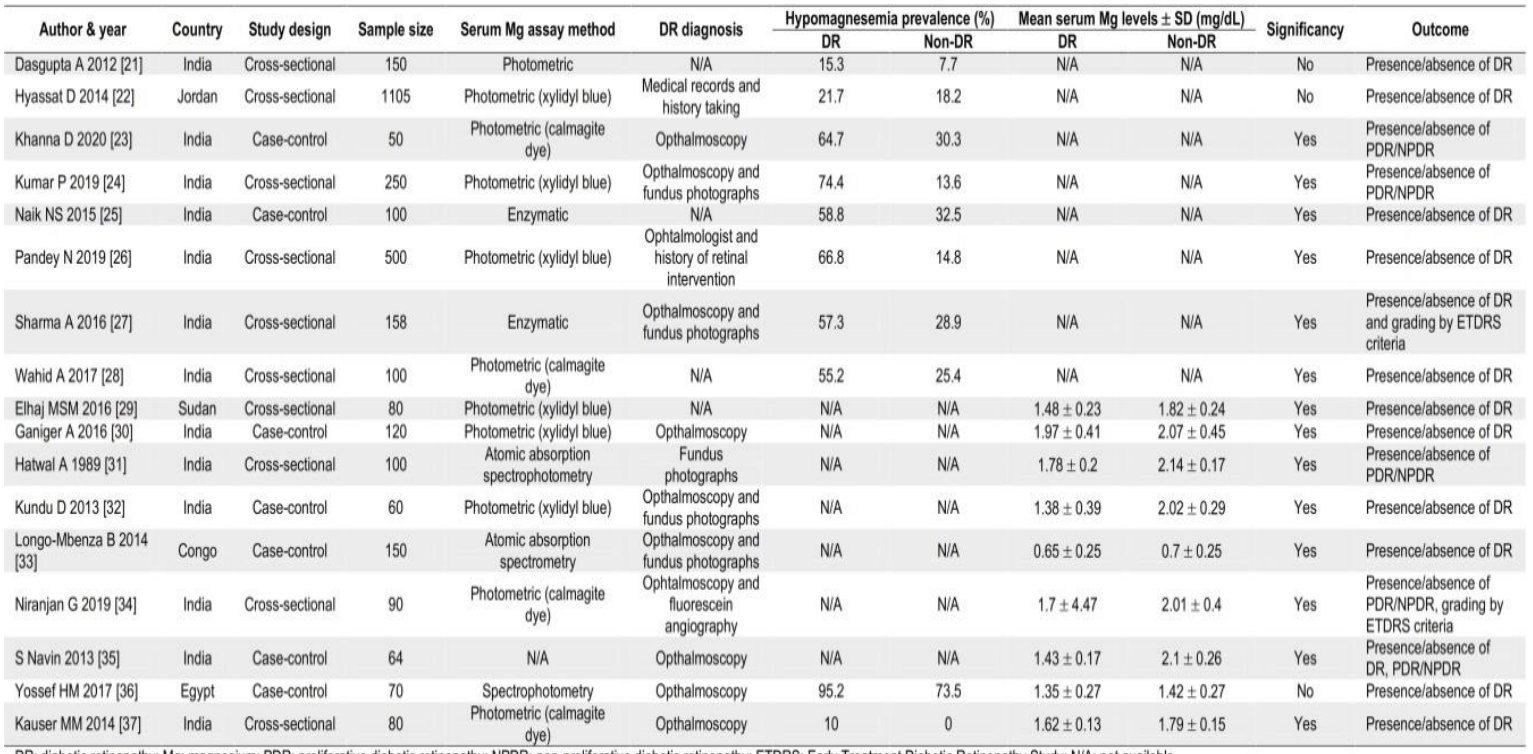

\subsubsection{Hypomagnesemia and diabetic retinopathy}

This present study showed that hypomagnesemia was associated with increased risk of developing DR (OR 4.52 [2.08, 9.81], $\mathrm{p}=0.0001)$, although significant heterogeneity was observed $\left(\mathrm{I}^{2}: 90 \%, \mathrm{p}<0.00001\right)$ as seen in Figure 2.

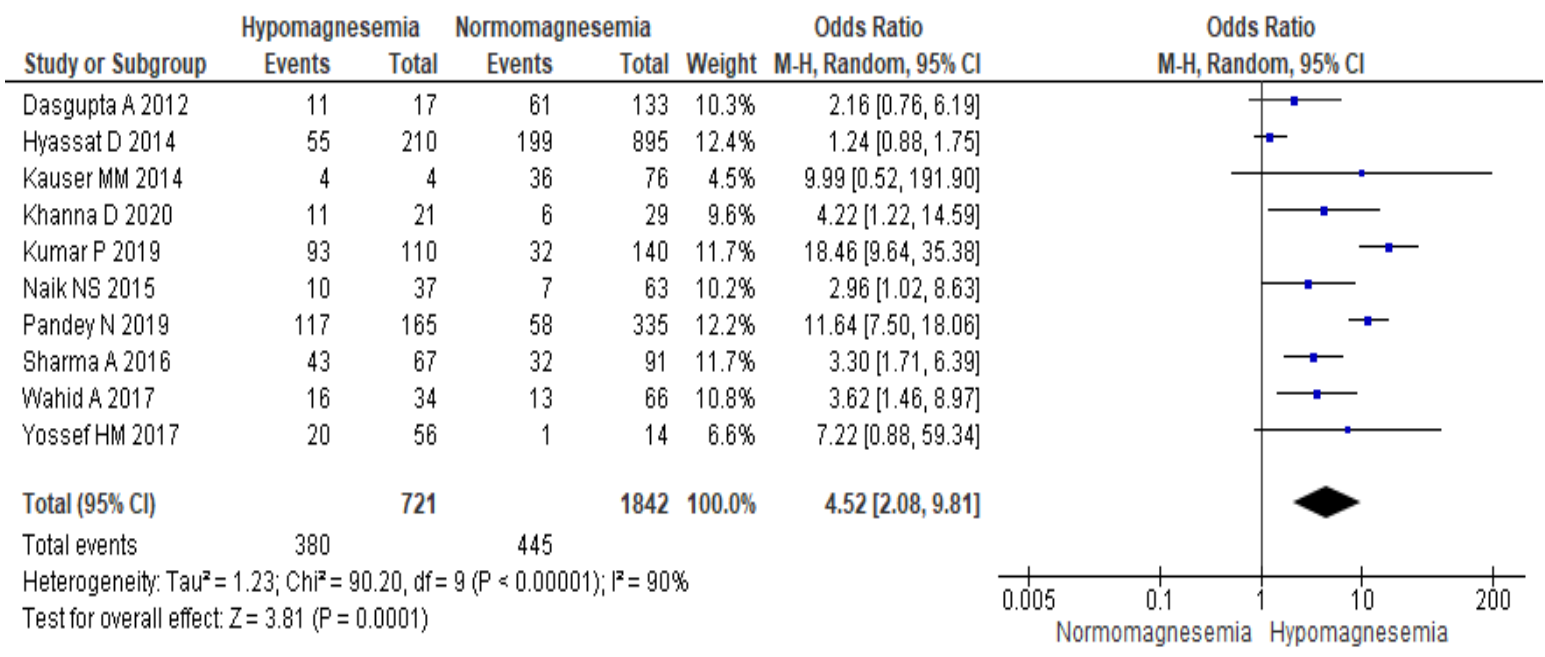

Figure 2. Association between hypomagnesemia and diabetic retinopathy 


\subsubsection{Serum magnesium levels and diabetic retinopathy}

Serum Mg levels were lower in patients with DR than those without DR (MD $-0.30 \mathrm{mg} / \mathrm{dL}[-0.44,-$ $0.15], \mathrm{p}<0.0001)$ despite the presence of significant heterogeneity $\left(\mathrm{I}^{2}: 94 \%, \mathrm{p}<0.00001\right)$ as represented in Figure 3. Additionally, serum Mg levels were lower in patients with PDR than those with NPDR (MD -0.21 $\left.\mathrm{mg} / \mathrm{dL}[-0.34,-0.09], \mathrm{p}=0.0009 ; \mathrm{I}^{2}: 48 \%, \mathrm{p}=0.15\right)$ as seen in Figure 4.

\begin{tabular}{|c|c|c|c|c|c|c|c|c|c|}
\hline Study or Subgroup & \multicolumn{2}{|c|}{ Diabetic retinopathy } & Total & \multicolumn{3}{|c|}{ Non diabetic retinopathy } & \multicolumn{2}{|c|}{$\begin{array}{c}\text { Mean Difference } \\
\text { Weight IV, Random, } 95 \% \mathrm{Cl} \\
\end{array}$} & $\begin{array}{c}\text { Mean Difference } \\
\text { IV, Random, } 95 \% \mathrm{Cl}\end{array}$ \\
\hline Elhaj MSM 2016 & 1.48 & 0.23 & 40 & 1.82 & 0.24 & 40 & $12.5 \%$ & $-0.34[-0.44,-0.24]$ & $\rightarrow$ \\
\hline Ganiger A2016 & 1.97 & 0.41 & 60 & 2.07 & 0.45 & 60 & $11.6 \%$ & $-0.10[-0.25,0.05]$ & \\
\hline Hatwal A 1989 & 1.78 & 0.2 & 60 & 2.14 & 0.17 & 40 & $12.9 \%$ & $-0.36[-0.43,-0.29]$ & $\rightarrow$ \\
\hline Kauser MM 2014 & 1.62 & 0.13 & 40 & 1.79 & 0.15 & 40 & $13.0 \%$ & $-0.17[-0.23,-0.11]$ & $\rightarrow$ \\
\hline Kundu D 2013 & 1.38 & 0.39 & 30 & 2.02 & 0.29 & 30 & $11.2 \%$ & $-0.64[-0.81,-0.47]$ & \\
\hline Longo-Mbenza B 2014 & 0.65 & 0.25 & 66 & 0.7 & 0.25 & 84 & $12.8 \%$ & $-0.05[-0.13,0.03]$ & $\rightarrow+$ \\
\hline Niranjan G 2019 & 1.7 & 4.47 & 60 & 2.01 & 0.4 & 30 & $1.5 \%$ & $-0.31[-1.45,0.83]$ & \\
\hline S Navin 2013 & 1.43 & 0.17 & 34 & 2.1 & 0.26 & 30 & $12.4 \%$ & $-0.67[-0.78,-0.56]$ & $\longrightarrow$ \\
\hline YossefHM 2017 & 1.35 & 0.27 & 21 & 1.42 & 0.27 & 49 & $11.9 \%$ & $-0.07[-0.21,0.07]$ & \\
\hline Total $(95 \% \mathrm{Cl})$ & & & 411 & & & 403 & $100.0 \%$ & $-0.30[-0.44,-0.15]$ & \\
\hline \multicolumn{9}{|c|}{$\begin{array}{l}\text { Heterogeneity. Tau }{ }^{2}=0.04 ; \mathrm{Ch}^{2}=127.76, \mathrm{df}=8(P<0.00001) ; 1^{2}=94 \% \\
\text { Test for overall effect: } Z=3.98(P<0.0001)\end{array}$} & 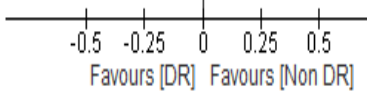 \\
\hline
\end{tabular}

Figure 3. Magnesium levels in diabetic retinopathy and non-diabetic retinopathy. Lower serum Mg levels were associated with diabetic retinopathy

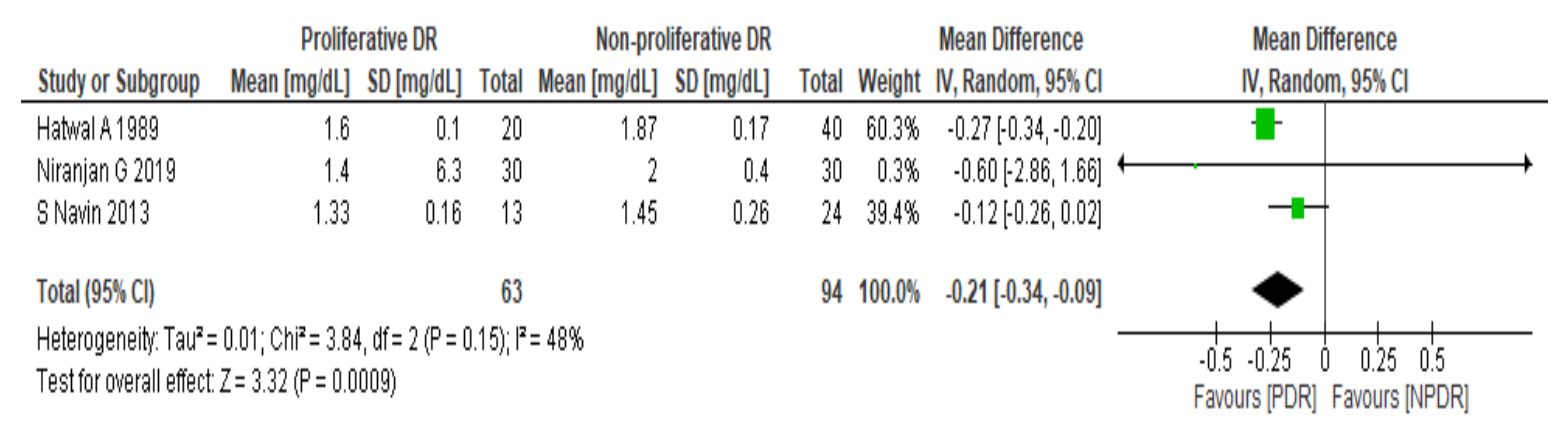

Figure 4. Magnesium levels in proliferative diabetic retinopathy and non-proliferative diabetic retinopathy. Lower serum $\mathrm{Mg}$ levels were associated with proliferative diabetic retinopathy

\subsubsection{Sensitivity and subgroup analysis}

Sensitivity analysis by leave-one-out was performed to single out the potential sources of heterogeneity in this study. In the result of the pooled OR, after excluding the study by Hyassat et al. [22] the heterogeneity was reduced to $72 \%$ (OR 5.53 [3.08, 9.94], p<0.00001). Further exclusion of any other single study did not significantly alter the pooled OR and heterogeneity. In the comparison of serum Mg levels MDs between group with and without DR, excluding the study by Navin et al. [35] slightly reduced the heterogeneity to $90 \%$ (MD $-0.24 \mathrm{mg} / \mathrm{dL}[-0.36,-0.12], \mathrm{p}=0.0001)$. Exclusion of any other single study did not significantly alter the overall MD and heterogeneity.

In subgroup analysis of study design, there were greater heterogeneities in cross-sectional study design $\left(I^{2}: 93 \%, p<0.00001\right)$ compared to case-control $\left(I^{2}: 0 \%, p=0.74\right)$ for the pooled OR (supplementary materials figure S1). Meanwhile, obvious heterogeneities were observed in both cross-sectional $\left(\mathrm{I}^{2}: 83 \%\right.$, $\mathrm{p}=0.0005)$ and case-control $\left(\mathrm{I}^{2}: 96 \%, \mathrm{p}<0.00001\right)$ study design for the overall MD result (supplementary materials figure S2). In the subgroup of serum $\mathrm{Mg}$ assay methods, the heterogeneities were higher with photometric methods $\left(\mathrm{I}^{2}: 92 \%, \mathrm{p}<0.00001\right)$ than with enzymatic method $\left(\mathrm{I}^{2}: 0 \%, \mathrm{p}=0.87\right)$ for the pooled OR (supplementary materials figure S3). For the overall MD, obvious heterogeneities were observed in both photometric $\left(\mathrm{I}^{2}: 94 \%, \mathrm{p}<0.00001\right)$ and atomic absorption $\left(\mathrm{I}^{2}: 97 \%, \mathrm{p}<0.00001\right)$ methods (supplementary materials Figure S4). 


\subsubsection{Publication bias}

Funnel-plot showed asymmetrical shape for both pooled OR and serum Mg levels MD Figure 5, indicating possible publication bias. However, Egger's test only showed small-study effects for serum $\mathrm{Mg}$ levels MDs ( $\mathrm{p}=0.009)$.
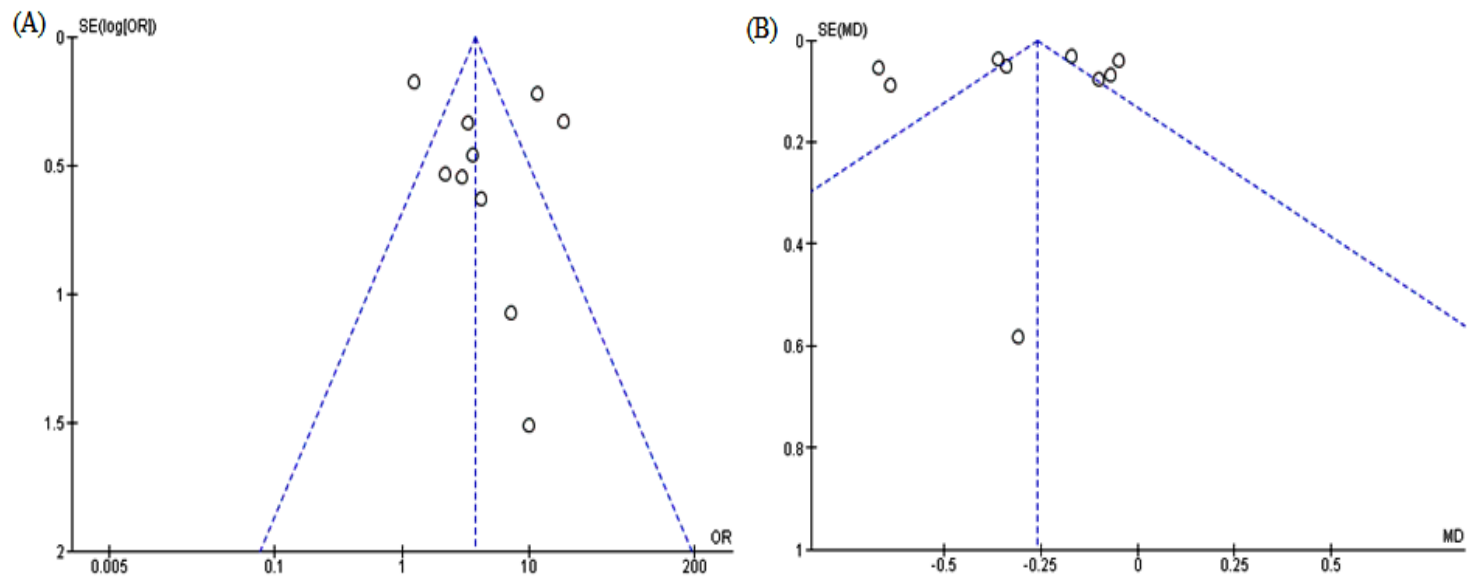

Figure 5. Funnel-plot analysis; (A) Asymmetrical funnel plots for hypomagnesemia in diabetic retinopathy and (B) $\mathrm{Mg}$ levels in diabetic retinopathy

\subsection{Discussion}

Magnesium as the fourth most common cation in the body was largely ignored up until recently. In recent years, the role of $\mathrm{Mg}$ in many fundamental biochemical and physiological processes has gained large interest. Magnesium is involved in: hormone receptor action, transmembrane ion transport, neuron activity, cardiac excitability, and vascular tone [38]. Changes in intracellular or extracellular Mg concentration may affect cell function through its effect on calcium handling. Due to its strong binding with Adenosine triphosphate (ATP) molecules, the majority of intracellular Mg is located within mitochondria. Metabolically active cell generally has higher intracellular $\mathrm{Mg}$ content. Meanwhile, plasma Mg levels of healthy people are maintained within narrow range of 1.7-2.4 $\mathrm{mg} / \mathrm{dL}(0.7-1.0 \mathrm{mmol} / \mathrm{L})$ [8], [39], [40].

Hypomagnesemia typically defined as having serum Mg levels below $1.6 \mathrm{mg} / \mathrm{dL}$, but it is commonly under diagnosed [41]. It might result from one or more of the following: reduced intake, impaired intestinal absorption, redistribution, increased gastrointestinal from diarrhea or renal loss. Thus it is recommended that $\mathrm{Mg}$ levels should be measured routinely in patients with conditions, diseases or treatment that may predispose to Mg deficiency [42]. Magnesium deficiency is prevalent in T2DM patients. Glucosuria impairs renal tubular reabsorption of $\mathrm{Mg}$ and accounts for a portion of the $\mathrm{Mg}$ loss [8], [41], [43]. Considering the various etiology of hypomagnesemia, the studies included in this meta-analysis must controlled for important confounders as: drugs known to affect $\mathrm{Mg}$ levels, presence of acute or chronic diarrheal/malabsorption states, taking supplements containing $\mathrm{Mg}$, alcoholics, and presence of other endocrine disorders.

Diabetes duration, poor glycemic control, nephropathy, hypertension, and dyslipidemia were established as modifiable risk factors for DR [5]. Magnesium deficiency is suggested as a possible novel risk factor for DR for the following reasons: i) Mg serves a fundamental role in energy metabolism, ii) retina is the most metabolically active tissue in the body, hence sensitive to hypoxia, iii) $\mathrm{Mg}$ has a vital role in the development and physiological eye function in experimental animal studies [7], [8], [18], [34]. The main result of our present meta-analysis provided evidence that hypomagnesemia and low $\mathrm{Mg}$ levels in T2DM patients increased the risk of developing DR (OR 4.52 [2.08, 9.81], $\mathrm{p}=0.0001 ; \mathrm{MD}-0.30 \mathrm{mg} / \mathrm{dL}[-0.44,-$ $0.15], \mathrm{p}<0.0001)$. The association between hypomagnesemia and DR remained significant in subgroup analysis of the study design and the serum Mg measurement method used. These findings were different with the study by Hyassat $e t$ al. [22] however, the non-significant result might be due to a higher proportion of subjects with poor glycemic control in group with normal Mg level.

The pathogenesis of DR is related to structural and functional changes in retinal vasculature [4], [44]. Although the mechanism of hypomagnesemia induced microangiopathy still unclear, evidences indicated that $\mathrm{Mg}$ deficiency sensitize vascular smooth muscle to various vasospasm inducing neurohormonal substances [45]. Magnesium deficiency also increases production of thromboxane A2, endothelin- 
1, and reduces prostacyclin production. Study of oral $\mathrm{Mg}$ supplementation in diabetic patients was shown to improve endothelial functions through increased nitric oxide (NO) production and induced vasorelaxation [46]. As retinal ischemia progresses, the vascular occlusion will induce expression of vascular endothelial growth factor (VEGF) which resulting in reactive retinal vascular proliferation [47], [48]. The latter is a marker of a more advanced form of DR, known as proliferative diabetic retinopathy. It is consistent with the result of the present meta-analysis which serum $\mathrm{Mg}$ levels were lower in patients with PDR than those with NPDR (MD $-0.21 \mathrm{mg} / \mathrm{dL}[-0.34,-0.09], \mathrm{p}=0.0009$ ).

Vascular dysfunction and repeated reperfusion injury will lead to increased oxidative stress and glutamate retention in retinal tissue [49]. The glutamate-induced excitotoxicity in neuronal tissues is mediated through $\mathrm{N}$-methyl-D-aspartate (NMDA) receptors which are coupled with voltage-gated calcium channels [50]. Being primarily regarded as calcium antagonist, in $\mathrm{Mg}$ deficiency, excessive calcium ions influx through NMDA receptors will take place. Calcium accumulation causes cellular swelling and cell death. Furthermore, excess calcium influx also causes oxidative stress with the generation of neurotoxic free radicals. In the presence of $\mathrm{Mg}$ deficiency, reduced activity of superoxide dismutase will lead to lipid peroxidation of Polyunsaturated fatty acids (PUFA) rich membranes by free radicals and impairs retinal function [18], [40], [47].

The main strength of this study is the strong evidence of the relationship between hypomagnesemia or low serum Mg levels in T2DM patients and increased risk of developing DR. However, our study has several limitations. First, the presence of publication bias which most of the studies are from India. Second, the studies included were observational by nature and mostly cross-sectional in design. Third, although the authors have made extensive efforts to ensure that all studies included controlling for the most important confounders (factors that might affect serum $\mathrm{Mg}$ levels); there were still diverse additional confounding factors across the studies (age, presence of microalbuminuria-nephropathy, diabetes treatments, diet). Lastly, only articles published in English were included in this study.

\section{CONCLUSION}

This present meta-analysis indicates relationship between hypomagnesemia or low serum $\mathrm{Mg}$ levels in T2DM patients and increased risk of developing diabetic retinopathy (DR). Magnesium deficiency will induce microangiopathy and excitotoxicity in retinal tissue. Still, further studies with other study design (prospective, retrospective cohort) are required; moreover randomized controlled trials to determine the effects of Mg replacement or supplementation on DR.

\section{REFERENCES}

[1] Sherwin R. and Jastreboff AM., "The Diabetes Tsunami," J. Clin. Endocrinol Metab., vol. 97, no. 12, pp. 4293-301, 2012, doi: 10.1210/jc.2012-3487.

[2] Shaikh MA, Gillani S., and Dur-E-Yakta, "Frequency of diabetic retinopathy in patients after ten years of diagnosis of type 2 diabetes mellitus," J. Ayub. Med. Coll. Abbottabad., vol. 22, no. 3, pp. 158-60, 2010.

[3] Yau JWY et al., "Global Prevalence and Major Risk Factors of Diabetic Retinopathy," Diabetes Care, vol. 35, no. 3, pp. 556-64, 2012, doi: 10.2337/dc11-1909.

[4] Cheung N., Mitchell P., and Wong TY., "Diabetic retinopathy," Lancet, vol. 376, no. 9735, pp. 124-36, 2010, doi: 10.1016/S0140-6736(09)62124-3.

[5] Solomon SD et al., "Diabetic Retinopathy: A Position Statement by the American Diabetes Association," Diabetes Care, vol. 40, no. 3, pp. 412-8, 2017, doi: doi.org/10.2337/dc16-2641.

[6] Wang W. and Lo ACY, "Diabetic Retinopathy: Pathophysiology and Treatments," Int. J. Mol. Sci., vol. 19, no. 6, pp. 1-14, 2018, doi: 10.3390/ijms19061816.

[7] Heng LZ. et al. "Diabetic retinopathy: pathogenesis, clinical grading, management and future developments," Diabet Med., vol. 30, no. 6, pp. 640-50, 2013, doi: 10.1111/dme.12089.

[8] Hans CP., Sialy R., and Bansal DD., "Magnesium deficiency and diabetes mellitus," Curr. Sci., vol. 83, no. 12, pp. 1456-63, 2002.

[9] Agus ZS, "Mechanisms and causes of hypomagnesemia," Curr. Opin. Nephrol. Hypertens., vol. 25, no. 4, pp. 3017, 2016.

[10] Pham P-CT, Pham P-MT, Pham S. V., Miller JM., and Pham P-TT, "Hypomagnesemia in Patients with Type 2 Diabetes," Clin. J. Am. Soc. Nephrol., vol. 2, no. 2, pp. 366-73, 2007, doi: 10.2215/CJN.02960906.

[11] Chaudhary DP., Sharma R., and Bansal DD, "Implications of Magnesium Deficiency in Type 2 Diabetes: A Review," Biol Trace Elem Res., vol. 134, no. 2, pp. 119-29, 2010, doi: https://doi.org/10.1007/s12011-009-8465-z

[12] Feng J. et al., "Role of Magnesium in Type 2 Diabetes Mellitus," Biol. Trace. Elem. Res., vol. 196, no. 1, pp. 74-85, 2010, doi: 10.1007/s12011-019-01922-0.

[13] Kao WHL., Folsom AR., Nieto FJ, Mo J-P., Watson RL., and Brancati FL., "Serum and Dietary Magnesium and the Risk for Type 2 Diabetes Mellitus," Arch. Intern. Med., vol. 159, no. 18, pp. 2151-2159, 1999, doi: 10.1001/archinte.159.18.2151. 
[14] Tu YF., Yu HY., and Li LX., "Association between serum magnesium level and 24-hour urinary albumin level in patients with type 2 diabetes mellitus," Chinese Gen Pract., vol. 15, no. 7, pp. 751-4, 2012.

[15] Takagi H., Kobayashi Y., Taguchi O., Takei Y., and Sumida Y., "Influence of dietary intake of fish oil, magnesium, and zinc on metabolic parameters among individuals tested for diabetes," Nutrition, vol. 31, no. 7-8, pp. 988-93, 2015, doi: 10.1016/j.nut.2015.02.019.

[16] Lee C-TC, Gayton EL., Beulens JWJ., Flanagan DW., and Adler AI., "Micronutrients and Diabetic Retinopathy," Ophthalmology, vol. 117, no. 1, pp. 71-8, 2009, doi: 10.1016/j.ophtha.2009.06.040.

[17] Goto Y., Furuta A., and Tobimatsu S., "Magnesium deficiency differentially affects the retina and visual cortex of intact rats," J. Nutr., vol. 131, no. 9, pp. 2378-81, 2001.

[18] Ekici F. et al., "The Role of Magnesium in the Pathogenesis and Treatment of Glaucoma," Int. Sch. Res. Not., vol. 2014, pp. 1-7, 2014, doi: 10.1155/2014/745439

[19] Modesti PA. et al., "Panethnic Differences in Blood Pressure in Europe: A Systematic Review and Meta-Analysis. Fuchs FD, editor," PLoS One, vol. 11, no. 1, pp. 1-21, 2016, doi: 10.1371/journal.pone.0147601

[20] Wells GA. et al., "The Newcastle-Ottawa Scale (NOS) for assessing the quality of nonrandomised studies in metaanalyses," 2014. [Online]. Available: http://www.ohri.ca/programs/clinical_epidemiology/oxford.asp

[21] Dasgupta A., Saikia U., and Sarma D., "Hypomagnesemia in type 2 diabetes mellitus," Indian J. Endocrinol. Metab., vol. 16, no. 6, pp. 1000-1003, 2012, doi: 10.4103/2230-8210.103020

[22] Hyassat D., AlSitri E., Batieha A., EL-Khateeb M., and Ajlouni K., "Prevalence of Hypomagnesaemia among Obese Type 2 Diabetic Patients Attending the National Center for Diabetes, Endocrinology and Genetics (NCDEG)," Int. J. Endocrinol. Metab., vol. 12, no. 3, pp. 1-7, doi: 10.5812/ijem.17796

[23] Khanna D., Bhatnagar M., and Tayal S., "Study of Serum Magnesium Levels in Type 2 Diabetes Mellitus," J. Evol. Med. Dent. Sci., vol. 9, no. 4, pp. 206-10. 2020, doi: 10.14260/jemds/2020/48

[24] Kumar P., Bhargava S., Agarwal P., Garg A., and Khosla A., "Association of serum magnesium with type 2 diabetes mellitus and diabetic retinopathy," J. Fam. Med. Prim. Care., vol. 8, no. 5, pp. 1671-1677, 2019, doi: 10.4103/jfmpc.jfmpc_83_19

[25] Naik N., Lamani S., and Devarmani S., "The role of serum magnesium level in type 2 diabetes mellitus," Int J Res Med Sci., vol. 3, no. 3, pp. 556-9, doi: 10.5455/2320-6012.ijrms20150305.

[26] Pandey N., Jain S., and Baghel PK., "Study of serum magnesium level in type 2 diabetes mellitus patients with special emphasis on microvascular and macrovascular complications," Indian J. Appl. Res., vol. 9, no. 11, pp. 3638, 2019; doi: 10.36106/ijar.

[27] Sharma A., Raj H., and Gupta A., "Risk Factors Associated With Diabetic Retinopathy In Type II Diabetic Patients: A Cross-Sectional Study," JK Sci., vol. 18, no. 1, pp. 50-54, 2016.

[28] Wahid A., Verma GC., Meena CP., and Pathan AR., "Study of serum magnesium level in patients with type 2 diabetes mellitus and it's correlation with glycosylated hemoglobin and diabetic complications," Int J Adv Med., vol. 4, no. 2, pp. 311-316, 2017, doi: 10.18203/2349-3933.ijam20170614.

[29] Elhaj MSM., Abd Elrahman SF., and Abdrabo AA., "Comparative study of serum Zinc and Magnesium levels among type 2 diabetic Sudanese patients with and without retinopathy complications," Sudan Med J., vol. 11, no. 3687, pp. 1-6, 2016.

[30] Ganiger A., Swamy KM., Gundalli S., and Kolekar R., "A comparative study of serum magnesium in type 2 diabetes mellitus with and without retinopathy and healthy controls and its correlation with glycemic status," Int J Clin Biochem Res., vol. 3, no. 1, pp. 6-10, 2016, doi: 10.5958/2394-6377.2016.00002.2.

[31] Hatwal A., Gujral AS., Bhatia RPS., Agrawal JK., and Bajpai HS., "Association of hypomagnesemia with diabetic retinopathy," Acta Ophthalmol., vol. 67, no. 6, pp. 714-6, 2009, doi: 10.1111/j.1755-3768.1989.tb04407.x.

[32] Kundu D., Osta M., Mandal T., Bandyopadhyay U., Ray D., and Gautam D., "Serum magnesium levels in patients with diabetic retinopathy," J. Nat. Sci. Biol. Med., vol. 4, no. 1, pp. 113-6, 2013, doi: 10.4103/0976-9668.107270

[33] Longo-Mbenza B et al., "Retinopathy in non diabetics, diabetic retinopathy and oxidative stress: a new phenotype in Central Africa?," Int. J. Ophthalmol. vol. 7, no. 2, pp. 293-301, 2014, doi: 10.3980/j.issn.2222-3959.2014.02.18.

[34] Niranjan G. et al., "Evaluation of Circulating Plasma VEGF-A, ET-1 and Magnesium Levels as the Predictive Markers for Proliferative Diabetic Retinopathy, Indian J Clin Biochem., vol. 34, no. 3, pp. 352-6, 2019, doi: 10.1007/s12291-018-0753-y

[35] S N, N K, S A, Dayanand CD, "The association of hypomagnesaemia, high normal uricaemia and dyslipidaemia in the patients with diabetic retinopathy," J. Clin. Diagn. Res., vol. 7, no. 9, pp. 1852-4, doi: 10.7860/JCDR/2013/6106.3332

[36] Yossef H., Ghanem N., Al-Jarhi U., and Shaker O., "Relation of serum magnesium level to microvascular complications and the components of metabolic syndrome in patients with type 2 diabetes mellitus," Egypt J Intern Med., vol. 29, no. 3, pp. 100-104, 2017, doi: 10.4103/ejim.ejim_22_17

[37] Kauser M., Afreen A., and Kasi J., "Study of Serum Magnesium Levels in Diabetic Retinopathy," J Res Med Dent Sci., vol. 2, no. 3, pp. 19-22, 2014, doi: 10.5455/jrmds.2014235

[38] Romani AMP., "Cellular magnesium homeostasis," Arch. Biochem. Biophys., vol. 512, no. 1, pp. 1-23, 2011, doi: 10.1016/j.abb.2011.05.010

[39] Musso CG., "Magnesium metabolism in health and disease," Int. Urol. Nephrol., vol. 41, no. 2, pp. 357-62, 2009.

[40] Ajith TA., "Possible therapeutic effect of magnesium in ocular diseases," J. Basic Clin. Physiol. Pharmacol., vol. 31, no. 2, pp. 1-6, 2019, doi: 10.1515/jbcpp-2019-0107.

[41] Pham P-C., Pham PA., Pham S., Pham PT., Pham PM., and Pham PT., "Hypomagnesemia: a clinical perspective," Int. J. Nephrol. Renovasc. Dis., vol. 7, pp. 219-30, 2014, doi: 10.2147/IJNRD.S42054. 
[42] Ozcan MS and Feld JM., "Hypomagnesemia," In: Fleisher LA, Roizen MFBT-E of AP (Third E, editors. Essence of Anesthesia Practice. 3rd ed. Philadelphia: W.B. Saunders; 2011. p. 201-2.

[43] Swaminathan R, "Magnesium metabolism and its disorders," Clin. Biochem. Rev., vol. 24, no. 2, pp. 47-66, 2003.

[44] Tarr JM., Kaul K., Chopra M, Kohner EM, and Chibber R, "Pathophysiology of diabetic retinopathy," ISRN Ophthalmol, vol. 2013, pp. 1-13, 2013, doi: 10.1155/2013/343560

[45] DiNicolantonio JJ., Liu J, and O'Keefe JH., "Magnesium for the prevention and treatment of cardiovascular disease," Open Hear., vol. 5, no. 2, pp. 1-10, 2018, doi: 10.1136/openhrt-2018-000775.

[46] Asbaghi O., Hosseini R., Boozari B, Ghaedi E, Kashkooli S, and Moradi S., "The Effects of Magnesium Supplementation on Blood Pressure and Obesity Measure Among Type 2 Diabetes Patient: a Systematic Review and Meta-analysis of Randomized Controlled Trials," Biol. Trace. Elem Res., vol. 199, no. 2, pp. 413-24, 2021, doi: 10.1007/s12011-020-02157-0.

[47] Agarwal R., Iezhitsa L., and Agarwal P., "Pathogenetic role of magnesium deficiency in ophthalmic diseases," BioMetals, vol. 27, no. 1, pp. 5-18, 2014, doi: 10.1007/s10534-013-9684-5.

[48] Gupta N. et al., "Diabetic Retinopathy and VEGF," Open Ophthalmol J., vol. 7, no. 1, pp. 4-10, 2013, doi: 10.2174/1874364101307010004

[49] Safi SZ., Qvist R., Kumar S., Batumalaie K., and Ismail IS Bin, "Molecular mechanisms of diabetic retinopathy, general preventive strategies, and novel therapeutic targets," Biomed Res Int., vol. 2014, pp. 1-18, 2014, doi: 10.1155/2014/801269

[50] Gupta PC., Sood S., Narang S., and Ichhpujani P., "Role of brimonidine in the treatment of clinically significant macular edema with ischemic changes in diabetic maculopathy," Int Ophthalmol, vol. 34, no. 4, pp. 787-92, 2014. 